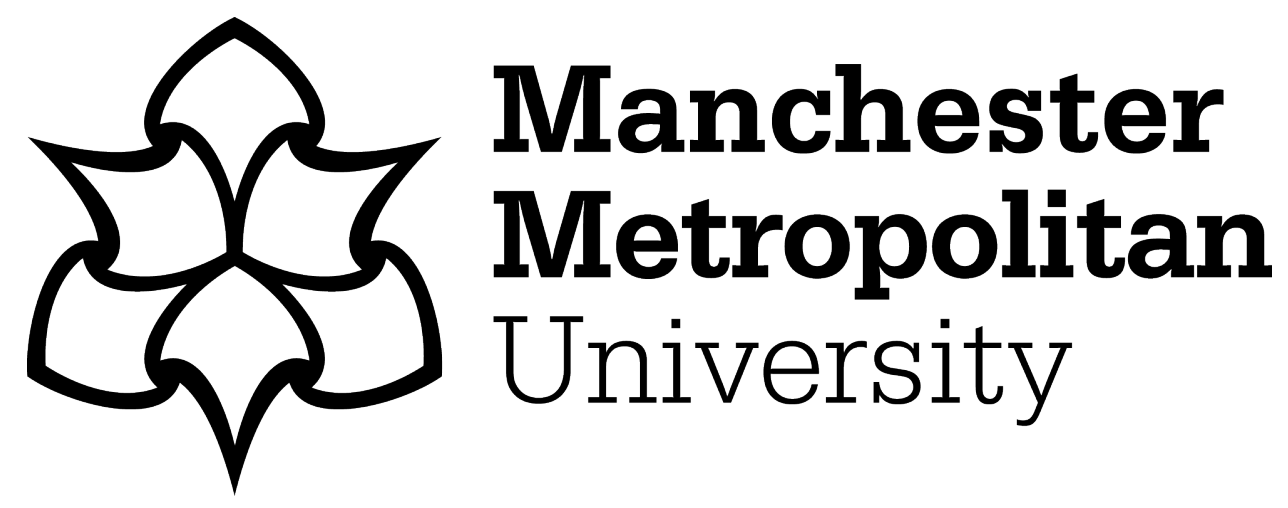

Zipin, L, Brennan, M and Sellar, S ORCID logoORCID: https://orcid.org/00000002-2840-5021 (2021) Young people pursuing futures: making identity labors curricular. Mind, Culture, and Activity, 28 (2). pp. 152-168. ISSN 1074-9039

Downloaded from: https://e-space.mmu.ac.uk/626531/

Version: Accepted Version

Publisher: Taylor \& Francis

DOI: https://doi.org/10.1080/10749039.2020.1808687

Please cite the published version 


\title{
Young people pursuing futures: making identity labors curricular
}

Lew Zipin (a), Marie Brennan (a), and Sam Sellar (b)

(a) University of South Australia; (b) Manchester Metropolitan University

Pre-published version accepted by the journal Mind, Culture, and Activity;

published version now online: https://doi.org/10.1080/10749039.2020.1808687

\begin{abstract}
Young people's processes of forming identities, linked to the work of anticipating futures, involve significant labors of thought, feeling, ethics and imagination. These labors proceed across both life-worlds and schoolworlds, often in tension, especially for those from marginalized positions in social-structural power relations. This paper explores such identity labors, drawing on rich ethnographic data from research, during 20132014, that engaged students in Years 9 and 10, from working-class, immigrant and refugee backgrounds, who attended an inner-suburban school in Melbourne, Australia. We investigate two student groupings: (a) selected by the school for "accelerated" curriculum paths; and (b) the "others" we label written off by the school in terms of academic potential (a division we diagnose as driven by policy measures of institutional "performance"). In different ways among students in each grouping, we find their identity labors to reflect historical conditions for what Berlant (2011) calls "cruel optimism" about futures. Yet their identity dynamics also draw on rich funds of knowledge from their life-worlds that our research shows to offer resources - funds of identity - for more viable future imaginaries. We argue for curriculum and pedagogy that supports young people in their identity labors to live from their present into emergent, new-generational futures.
\end{abstract}

Keywords: funds of knowledge; funds of identity; aspirations; futures; cruel optimism 


\section{Introduction: Life-world identity labors towards futures in cruel times}

The Funds of Identity (FI) approach to school curriculum (Esteban-Guitart \& Moll, 2014a, 2014b; Esteban-Guitart, 2016) draws from, and extends, the Funds of Knowledge (FK) tradition, which researches for, and builds curriculum units around, "historically accumulated and culturally developed bodies of knowledge" (Moll, Amanti, Neff \& Gonzalez, 1992, p. 133) that hold meaningful use-value in students' family and community life-worlds. Emphasis here is on "historically accumulated" cultural resources: i.e. inherited from the past. The FI approach shifts emphasis towards how young people in the present - as they put inherited resources to work in life, and in designed curriculum - create new-generational resources towards emerging future identities. Esteban-Guitart (2016, p. 48) thus conceives that, as young people work their inherited FK "into self-conception and self-expression" - as "funds of identity" - they "re-create particular funds of knowledge." The FI approach thus sees identity-information as a dynamic process that, working upon inherited knowledge resources, extends the vector of lived time: from past-in-present, to present-into-future.

In this article we extend the FI lens for seeing identity-formation as active and future-oriented, with further insight from pragmatist philosopher William James, who, in The Will to Believe (1896, n/p), said:

\footnotetext{
A live hypothesis is one which appeals as a real possibility ... measured by [one's] willingness to act.... Options may be of several kinds. They may be (1) living or dead, (2) forced or avoidable, (3) momentous or trivial; and for our purposes we may call an option a genuine option when it is of the forced, living, and momentous kind.
}

James here refers not to scientific hypotheses but to felt senses of "genuine options" for carrying on from present into futures. Such existential hypotheses emerge, and are tested, not by evidentiary proof but in the inter-subjective phenomenology of daily 
social living, wherein people sense "real possibility" that incites a will to believe and act. However, the future-animating viabilities of hypotheses are tested anew, and may wane, as people live them over time in changing social-life contexts. James names three criteria that test ongoing vitality of hypotheses into futures: they are forced, not avoidable; momentous, not trivial; and, crucially, they sustain a living, not dying, optimism about future prospects.

This article analyzes data from a research project in Australian high schools which investigated how students in Years 9 and 10, from power-marginalized families working-class and refugee/immigrant - form aspirations towards futures as they "read the worlds" of their present. Resonant with FI's, and James', future-oriented insights, our project proceeded from a premise that, laced within funds of knowledge, is "an emergent dimension ... of cultural threads that carry potentials to verge away from precedents in the past, towards alternative future possibilities - that we call funds of aspiration" (Zipin, Sellar, Brennan \& Gale, 2015, p. 239).

The word aspiration suggests hypotheses alive with optimism about future options that, says James, "appeal as real possibilities" impelling belief and active pursuit. Yet our research raised questions about whether "the future" itself - as an overarching hypothesis, and in specific imaginaries - impelled optimistic belief among the young people with whom we engaged. In terms of James' three-fold criteria for "a genuine option," "the future" is of course forced (not avoidable) and momentous (not trivial). Yet these students expressed senses of futures that suggested difficult identity labors to generate livingly persuasive imaginaries of hopeful futures emerging from present contexts. We found them to anticipate struggles and disappointments, reflecting what Berlant (2011) diagnoses as widespread material-historical conditions of "cruel optimism" in life-worlds increasingly fraught with obstacles both: (a) to what, in past 
contexts, might have been reasonable strategies for pursuing futures; and (b) to imagining alternatively viable trajectories into futures.

Registering “cruel," or “dark,” times, in our data-analyses, gives grist and extension to Esteban-Guitart's view (2016, p. 30) that "[t]he past is no longer as useful for understanding the challenges of a future that is too uncertain and changeable." Data from our student participants indeed suggests cruelly precarious challenge to optimism in their identity labors towards futures. We use the term "identity labors" - rather than the more usual "identity work" - to signify the strenuousness of their identity efforts, borrowing from the term "emotional labors," and with a sense of labors to give birth. How young people's anticipations of futures take form is a socially emergent phenomenon of complex identity labors, involving emotive and ethical as well as cognitive dimensions. We found that the schools where we researched did not support such future-oriented identity labors. We argue that schools should make such identity labors curricular, drawing on young people's FK, as an urgent priority if "the future" is to engage young people as a live aspirational hypothesis.

\section{School-worlds and policy regimes: Limited space for rich identity labors}

In Australia, like other "advanced capitalist" nations, young people from age 5 through 17/18 spend many hours in schools, in addition to family and - increasingly into adolescence - peer and adult life-worlds beyond school. Identity labors across all these social spaces feed formation of hypotheses about futures.

FK/FI projects seek rich linkages of "life-world" and "school-world" knowledge via curriculum activities. Although school and beyond-school "worlds" are all lived social spaces, we call the former "school-worlds" to signify institutional confines that can limit knowledge-permeation from fuller social-life spaces. The knowledgeorientations of these two "worlds" thus come into tension. What we call "life-world" 
knowledge comprises a complex mix of diverse kinds of sense: from powerfully circulated "commonsense," to organic senses that build knowledge bodies across community cultural-histories. FK/FI approaches seek community-based knowledges holding meaningfully rich use-value, around which to build curriculum units linked to rich registers of school-subject knowledge. However, if school-subject knowledge is not equivalently open to life-world knowledge richness, then - as our data will illustrate students often read their wider social worlds, including likely emergent futures, with more sophistication than school discourse about their futures.

We find that current policy-ordained curriculum is not open to rich life-world knowledge. National curricula in Australia and elsewhere fetishize "disciplinary knowledge" from universities as imparting "powerful" capacities to learners that lifeworld knowledge supposedly lacks (Muller \& Young, 2019). In thereby dismissing the learning value of life-based knowledge, policy-makers fill national curricula with content fragments that dilute the university-based knowledge they re-contextualize. Students are thus not brought into robust thought processes connected to problems that matter to their futures (Zipin, 2017, 2020).

Policy also ordains measurements of performance, circulated in league tables in Australia, the government-sponsored My School website that compares "likeschools" (based on socio-economic status) - under the guise of "informing parent choice." This leads to niche-market competition, pushing "like-schools" into an institution-centric focus on how they perform in response to power-pulls of policy, undermining regard for local communities, especially marginalized communities lacking power to leverage their needs and aspirations.

In this article, we explore how Year 9 and 10 students in one school, which we call Fringe City College (FCC), draw on diverse resources for identity labors, supported 
by our project's research processes that engage them in reflection on family, school and wider community worlds. The next section situates FCC in its local context and briefly explains our methodological approach. Ensuing sections provide data-rich illustrations and analyses of students' identity labors in which they diagnose historic conditions that cruel their optimism, and so they struggle for hypotheses about futures that encourage a "will to believe."

\section{Research context and methodologies}

Our project, "Capacitating student aspirations in classrooms and communities of a high poverty region," "was situated in suburbs west and northwest of Melbourne, capital city of the state of Victoria. In Australia, most urban dwellers live in suburbs surrounding cities, into which they travel for employment and/or cultural activities. Inner suburbs have historically reflected class/ethnic diversity, although recent gentrification pushes power-marginalized groups increasingly to outer suburbs.

The school is located in an inner suburb that we call Fringe City (FC). After WWII, FC's industrial jobs and affordable housing drew both Australian-born workingclass and European immigrants. Schools were not a crucial path to such industrial jobs. After the official White Australia policy ended in 1967, Asian and, more recently, African groups added to the demographic mix. Industrial employment sustained a postwar social-democratic policy settlement to keep wealth distribution within a workingmiddle range (still, unofficially, benefitting "Whites" while Indigenous and other "nonWhite" groups remain marginalized). Since the 1980s, however, rising stratification,

\footnotetext{
${ }^{1}$ This project, funded by the Australian Research Council (DP120101492) 2012-2016, included Research team members Lew Zipin, Marie Brennan, Sam Sellar, Trevor Gale and Iris
} 
declining industry and insecure work - associated with neoliberal restructuring - have put more weight on school "success" for life-chance pathways.

FCC has not "won" in competition with nearby "like-schools" for students from new-gentry pockets moving into the area. FCC thus inherits poorer working-class and refugee-immigrant students, about 50\% from language backgrounds other than English, and over 50\% below Australia's socio-economic average. Rather than take this as incentive to develop a multi-cultural, FK-rich curriculum, FCC (like other Victorian schools serving structurally less powerful groups) creates curriculum divisions under market-pressures to bolster school performance metrics. It selects a small sub-cohort, deemed "high-achievers," for "accelerated" classes in Years 7-9, tracking to the state's academic certificate for university access - the Victorian Certificate of Education (VCE) - in Years 11/12, with pre-VCE classes in Year 10. The larger body of students include: (a) some who, while not "accelerated," aim for VCE; and (b) a significant number who are steered into the state's vocational certificate - the Victorian Certificate of Applied Learning (VCAL) - that bars university access. In complex ways such tracking boosts school metrics, but at the expense of many power-marginalized students whom the division further marginalizes.

In 2013, sitting in as ethnographers on Year 9 classes, we encountered this separation between students whom - regarding how the school sorts them - we call "selected" and "written-off" (a term we heard some teachers informally use, and which - as our data will show - such students sense in how the school treats them). We explained our project's interest in young people's aspirations towards futures, and facilitated in-depth focus groups with Year 9 students who volunteered. We further explained that, in 2014, our team and an FCC teacher would conduct a Year 10 elective 
class in which students, in small groups, undertake research to investigate local issues they identify as mattering for their own, their families' and communities' futures.

These focus-group and student-as-researcher methods extended FI approaches that focus on students creating "identity artifacts" (Subero, Vujasinović \& Esteban-Guitart, 2017). In working with older adolescents, aged 14-16, we sought methods for making curricular use of their expanding range of life-world familiarity and knowledge, in complex interaction with school-world affordances and constraints. We thus aimed to push FK/FI curriculum work towards fuller two-way connection between school- and life-worlds, emphasizing the sociality of young people's identity labors, and supporting them to develop their "capacities to aspire" (Appadurai, 2004): capacities for imagination, voice and other dimensions of future-creating agency.

Ensuing data-and-analysis sections focus, first, on the Year 9 focus-group data, featuring "selected" students"; and then on data from the Year 10 elective class, featuring “written-off” students.

\section{Cruelled optimism among "selected" students}

The focus groups - four sessions of 1.5 hours each, facilitated by Lew (co-author of this article) - drew a consistent core of "accelerated" students. In the first session, Lew framed the purpose as inquiry into thoughts and feelings about verging futures. $\mathrm{He}$ suggested that conditions of different times and places underpin different moods between optimistic and pessimistic - in relation to issues that matter to young people's senses of futures, which he invited participants to identify. While climate change, racism and other concerns were touched on across sessions, focal to all sessions were anticipated trajectories through education into socio-economic prospects. 


\section{"A different generation"}

Discussion began with participants identifying as "a different generation" from parents:

Irene: It's really difficult to get jobs in the economy so it's kind of a stressful thing. Rhonda: [Higher Education] debts that we are going to be paying for the rest of our lives ... [are] not exactly a comfortable thing to think about ... It is more difficult for us, because our parents all got free [university].... Our families might not be really wealthy ... [but] they were more comfortable throughout their early adulthood. They weren't worrying about all of these kind of things that we have to think about.

Denise: Our parents want us to go to university, but ... that it is not a guaranteed successful career.

Rhonda: Yeah, we have lost that safety blanket: you go to university; you automatically get a job. It is not like that now; it is a different generation.

From WWII into the early 1990s, a widespread optimistic hypothesis among Australian families, borne out for many, was that children's life chances would mobilize upward from parents. Within a policy settlement that, compared to the USA and UK, supported a more egalitarian working-middle class range, Boomer-generation young people could advance in prosperity without university degrees or even high school completion. In 1973, as life-chance advancement linked more with university degrees, government policy established free university access across the class spectrum, from which Gen-X parents of these focus group participants benefitted as first-in-family to enter university. From 1989, however, fees returned and gradually rose - and with this, debt - alongside university massification, credential inflation, and job scarcity for young people.

Registering this precarity, focus-group participants form a hypothesis of downwardly mobile Gen-Z futures. They noted older siblings and cousins struggling to parlay university degrees into jobs. However, their most graphic evidence of the dying viability of an upward-mobile hypothesis was tales of parents crashing into walls of 
mid-life disruption to more comfortable early-adult trajectories. Their exchanges of family stories activate identity labors of difficult thought-and-emotion.

Mary, whose father parlayed an IT degree into limited-term consultancies with companies, explains how early viability of this entrepreneurial path has hit obstacles:

My dad was unemployed for seven months [last year] after he was let go by a company. Most companies will have you on short term ... then you have to think about afterwards ... He actually had to take a secondary course in order to get more opportunities because of his age [in his 40s].... My mum works a full-time job ... [so, while] we weren't making enough money to keep our heads above water, ... [dad couldn't] go on unemployment, which was really hard for us.

Mary's testimony signifies how current economic precarity does not elude "knowledge economy" and "entrepreneurial" pathways that neoliberal policy hypotheses promise. Consequent family insecurity affects Mary's mood about futures she might desire. She and her parents participate in a theatre group - "my favorite thing," said Mary - which led her to choose FCC (strong in performing arts). Yet she adds that theatre must be "artistic as a hobby," not imagined as a career; rather, she "use[s] art as a way to get away from life's struggles."

Following Mary's testimony, Lew asked the group: "If this were the kind of world that let young people do what they really wanted, what would it be?" Nate promptly responded: "I think 90\% would be artists and writers." Yet, joining Mary’s reality-checked woes about creative possibility, he told how his father - also first-infamily to attend university - struggles in aspiring to earn a living writing scripts:

My dad has been trying to get into [that] career for such a long time, like twenty years to twenty-five years, and he has not been able to do it. And now he is just teaching. 
"Just teaching" signifies, to Nate, downward mobility in terms of material comfort achieved by Nate's grandparents:

My grandparents were born pretty poor but ... [now] live in [relatively wealthier] eastern suburbs ... [T] hey help out [at] old people's homes; I think it's because they started off poor, so they still have a [working-]class idea of friendliness.

Thwarted hopes for creative paths are not unusual for offspring whose Boomer parents gained material comfort, and who could shift to pursue other middle-class options. Yet, in the mood in which Nate and his Gen-Z peers anticipate weaker options, the insecurity in his father's creative struggles symbolizes a future he feels urgent to avoid. $\mathrm{He}$ formulates the counter-imaginary of a stable beginning-middle-end career progression:

It is hard for my dad ... because there's so many people going for the same thing, you have to work so hard, and ... it's still not a guarantee.... My parents are both all about the creativity. But I am the complete opposite. I don't want to have anything to do with art ... I think my dad is kind of disappointed about that.... I want to join the Army and I just love the fact that you are with a small group of people for a very long time, like working with them - yeah, the camaraderie.

Joining in, Rhonda picks up Mary's “head above water" metaphor, and Nate's theme of perilous creative pursuit, in telling of her parents' entrepreneurial perils:

They both did Fine Arts degrees. My dad is an antique dealer. My mother stud[ied] writing. And it is difficult for them to keep their heads above water, absolutely. My dad owns his own company ... [but] he's not getting all of these extra kind of things ... and he's constantly carrying heavy things ... [despite aging] fragility of his body ... [He feels] bitter resentment ... I don't want to have that kind of career where you're stuck doing something; but that seems like most of our parents. As a last resort I want to do something that I enjoy.

Like Mary's father, Rhonda's father's small-business path lacks benefits provided by securely salaried careers that have faded, as options, in a risk-society. She thus sees 
through simplistically optimistic government and media hypotheses about university degrees leading to good entrepreneurial lives. Empathizing with her father's bitterness in finding himself stuck in such false promise, Rhonda struggles for a hope-invested hypothesis of future work she can enjoy. Yet this "last resort" impulse fails to find viable content that a genuinely aspirational imaginary needs.

Taking up the "getting stuck" motif, Denise injects notes of frustration with parents who press the hypothesis that university degrees mean good futures:

The reason my parents want me to go to university is ... [so] I don't get stuck in a boring job. They are not getting that I probably will get stuck in the same job as my mum, in retail which she is getting really sick of ... But mum is like: "No, you're going to university and do something like teaching or law or doctor or nursing."

Denise's mum conjures university as the path to middle-class (teaching, nursing) and professional-class (law, doctor) options that Denise critiques as unviable. In emotive tones of impatience, she rejects what she sees as a simplistic hypothesis, "not getting" the complex lived contexts wherein she and peers foresee likely futures. While Rhonda also doubts the hypothesis, she parses complex emotive urgencies within the simplistic parental discourse:

My mum [feels] ... that we're [Rhonda and siblings] not privileged enough [and] should have more ... They feel really bad ... [which] makes me feel bad. Our parents try and hide the struggles from us because they don't want us feeling this pressure but it is inevitable that we do ... We realize how it's going, or how we think it is going to be and hope it is not going to be.

Rhonda expresses affective identity labors of sympathy with her parents even as she affirms her generation's grounds for different expectations. Indeed, empathy towards her parents for efforts to hide mid-life struggles and emotions that they suffer adds to Rhonda's anguish about her dimmed hopes for desirable futures. Her insight into their 
abject emotions reflects Berlant's (2011) diagnosis that "subjects of precarity ... have chosen primarily not to fight, but ... to stay in proximity to some aspirations that had gotten attached to the normative good life" (p. 249) because, as “cruel optimism's double bind, ... it is awkward and it is threatening to detach from what is already not working” (p. 263). Her parents thus still try to convince Rhonda, and themselves, that "what is already not working" might still work.

Across their dialogue, these young people, in their identity labors, subject the neoliberal promise - that young people can parlay university degrees into trajectories of entrepreneurial success - to critical observation. They find it a simplistic and false hypothesis, not compelling belief: an "opportunity trap" couched in a false "opportunity bargain” (Brown, Lauder \& Ashton, 2010). Rather than upward-mobility, they discern “precariat" futures (Standing, 2011), already graphic in parental plights, as "the experience of middle Australia" wanes (Pusey, 2003) and people either stumble downward (the many, including them) or claw upward (the few).

\section{School's performative pressures}

FCC staff also push simplistic hypotheses at these "accelerated" students, but which they sense come from different underlying urgencies than those of parents: i.e. the school's market-competition incentives. Irene and Rhonda begin a critical dialogue:

Irene: [Teachers] say electives in Year 9 and 10 will help you get into your VCE electives, which will help you with your pre-reqs for your uni courses, which will lead to your career... Well, in Year 9, I have no idea what I want to do. I am 15: when I pick electives, let me choose what I want.

Rhonda: Teachers say to us, "You know, you have got to start thinking about ... what is the career that you are going to do." It is not true, because on average a person has ... three or four jobs in their lifetime. It is ridiculous to put all this stress on [us when] ... going through the stress of being a teenager as well. 
Irene and Rhonda do not simply resent absurdities of rushing adolescents into knowing what "careers" they want. They also doubt school promises that its "accelerated" program furthers gainful and stable careers in futures of increasingly casualized work. If the meritocratic hypothesis - that good futures are earned through hard work in school seemed viable among their parents, it no longer holds - as what James means by a "live hypothesis" - in their identity-labors towards futures. Moreover, they intuit that school pressures on them to perform are not about their "careers" but the school's institutional urgency to "perform" in market-competition:

Irene: They expect you to know more; so the teacher is: "Why don't you know this, you are in the high achievers class?"

Rhonda: Teachers have actually said: "You have to set a good example because you are supposed to be smarter than all of the other kids".... Which is absolutely not true, there's so many smart kids in all of the other classes that just don't come into our class because they know all of the pressure that they put on us.... [What] makes it all the more difficult ... [is I've] given up caring; I mean I still do my work but I don't really care anymore: I don't enjoy it.

In emotive terms, Irene and Rhonda express abject hurt from teachers burdening them with pressure to "achieve highly" and insinuating they may be "less smart" than FCC had banked on. In this way, the school's insecurities of market position diffuse into, and heighten, student insecurities about futures, intensifying bleak anticipations of a long, hard, soul-killing slog to achieve university places that offer no "good-life" guarantees.

\section{Acute pessimism summons ethical will}

In telling dialogue, the group's struggles for their own viable hypotheses of futures reach a crescendo that combines identity labors of thought, emotion and ethics:

Nate: You can't expect that your future is just going to happen [as you want] ... They [teachers] go: "Okay, here is your idea, and now come and we'll do it our 
way instead of doing it your way.... It's, like, "reality," but it's not the right thing: it's not how it should be.

Mary: It's unfortunate that it is like that.

Nate: The way that our world works, you have to be so practical and everything is so calculated... You can always have your dream, but there is no guarantee ... You have to work so hard ... [and] still, you might not be able to do it.

Rhonda: Unfortunately I think that there are so many situations you kind of have to pay your dues. Are we really just pessimistic? It is a really, really pessimistic generation!

The emotive pains of identity labors within frames of no-longer-working "optimism" here take a turn. Nate invokes teachers' simplistic hypothesis of "reality," which the group has tested as wanting, against more complex realities that they live. Yet, suggests Rhonda, it is unfortunately real that they pay dues to powerfully imposing hypotheses about "reality": a basis for woeful pessimism in pursuing futures. Yet Nate poses an ethically dynamic test by which the imposed hypothesis is unacceptable not just as false "realism" but as "not the right thing": i.e. accepting it forecloses agency to pursue alternative ways "it should be," as an ethical right of young people to live their present towards desirable futures that they labor to create.

A weight of obstacles to such agency was stated by Jonah, who came only to the final session but was aware of prior discussions from friends in the group:

There's parts of what we are doing that could lead to something better, but it's just a very little speck of light in a very dark place ... Our parents are working harder now, and it's that fear that we're going to have to start off in that very hard stage and then either could get even harder or it might die down; it's the unknown which is scary.

Jonah's "speck of light" within a vast "dark place" registers Berlant's sense of materialhistorical conditions underpinning “cruel optimism.” Says Berlant (2011, p. 24): 
What's cruel about these attachments, and not merely inconvenient or tragic, is that ... subjects might not well endure the loss of their object/scene of desire, even though its presence threatens their well-being, because ... [it provides a] sense of what it means to keep on living on and to look forward to being in the world.

Berlant implies that human subjects, if they are to live in pursuit of worldly futures, have ontological need for what Gramsci (1971) calls "optimism of the will” (resonating with James "will to believe") to counter "pessimism of the intellect" that materialhistorical contexts warrant. How, then, might schools help capacitate young people's identity labors with agency to imagine and pursue potentially (far from guaranteed) more optimistic futures out of currently cruel social-historical contexts? Instead of thwarting students' forward-looking impulses through curriculum that clings to normative hypotheses that no longer work, schools should invite students' to convert their funds of knowledge, via curriculum activity, into resources - funds of identity - for future-oriented labors. We suggest that, in the above dialogues among "accelerated" FCC students, they brought to bear rich life-based knowledge about families in plight that constitute a form of what Zipin (2009, 2013; Zipin, Sellar \& Hattam, 2012) calls "dark funds of knowledge,"2 which can transmute - via curriculum work - to dark-yetrich "funds of identity" for agentic grappling with life-world conditions associated with structurally unjust forces of poverty, racism, sexism and more. This argument extends

\footnotetext{
${ }^{2}$ As our data suggests, the prefix "dark" is not pejorative in connotation. It does not signify a negativity, or deficit, in either "dark FK" or those who embody it. Rather, it signifies rich knowing about lived conditions associated with social-structurally "dark" injustices of poverty, racism, sexism and more. Zipin (2009) noted that young people's FK about "darkside" life conditions was turning up in his and colleagues' research, yet was absent in most literature about FK praxis that seemed to build curriculum units only around "light-side" FK (nor does "light" here signify less substantive or less worthy knowledge).
} 
into the next section, which turns to the identity labors of "written off" students whom our project engaged in curricular units of local-community research.

\section{“Written-off" students: Doxic fantasy, dire pessimism, dark funds, and imaginative leaps}

Year 9 focus-group participants all expressed interest in the Year 10 elective class, "Researching FC Futures," run in Semester 1, 2014 by Lew and an FCC teacher (both "White" males; Lew from professional-class, the teacher working-class background). Yet none enrolled because the school had, at the same times, scheduled pre-VCE classes they needed for access to their chosen VCE paths in Years 11/12. There were some VCE-bound students, without such schedule conflicts, in the class, five of whom White, of mixed gender - grouped around the research topic "future FC yuppification": a gentrification trend they resented, affirming their working-class identities. Another four VCE-bound students - male and diversely Asian-immigrant - grouped around the topic "future housing affordability," indicating concern that, unlike for their immigrant parents, homes in the area might prove too costly for them. All other students had no pre-VCE classes in their schedule, and were assumed by school administrators to be VCAL-bound (although final decisions are not made until late in Year 10). Four, who were White of mixed gender, and lived in a poor suburb with drug and gang issues, grouped around the topic of "future street safety." Four Ethiopian refugees - three sisters (of different ages, yet placed in the same Year-level) and one male - researched "Ethiopian business futures in FC" as it gentrifies.

Below, we focus on a group of four with whom Lew worked closely: Eaman, a male Sudanese refugee; Iaka, a male Māori (Indigenous New Zealand) immigrant; and two "White" Australia-born females, Geri and Tanya. The group's topic was "future race relations" as FC gentrifies. As ensuing data shows, these four embodied rich FK, 
much of it based in "darker" dimensions of lived experience, that fuelled identity labors in their work in this class, which the wider school wrote off in terms of curricular worth, inciting their disengagement from schooling.

In early dialogue, before their research began, Lew queried the four on whether they anticipated university in their futures:

Lew: Eaman, do you think that you are going to go to Uni?

Eaman: For sure.

Lew: And where do you think Uni will get you?

Eaman: A job.

Iaka: It will get me rich.

Eaman: Yes, it will make me a better businessman.

Lew: So how are you going in school now? Does it look like it's getting you there?

Eaman: I was thinking about doing TAFE because I missed out ... [and] I was embarrassed ...

Iaka: School's going good. It's going to get me rich

Eaman: I am going to be a businessman. That's all I want

Geri: What do you want to do in business? What exactly do you want to do ... be a car salesman? Do you want to sell things online? Do you want to be telemarketer?

Eaman's response is of a kind that Zipin et al. (2015, p. 232) call "doxic fantasy": i.e. when "desires for upward mobility, among those whose accumulations of economic, social and cultural capital for pursuing them are not strong," nonetheless fixate on masscirculated norms (doxa) about goals to which all should aspire. We note that Eaman's refugee father has set up a fledgling bicycle repair shop. Perhaps Eaman buys into a family-nurtured doxa of Australia as a promised land of capitalist opportunity to advance. In any event, Eaman and Iaka egg each other on in their "rich businessman" hypothesis, as if adamant wishing can make it so.

Yet Eaman exposes how his will, in this case, lacks real belief. He foresees not university but Technical and Further Education (TAFE) - a vocational tertiary sector - 
after embarrassing messages from FCC staff that he is "missing" what's needed for VCE academic demands that lead to university. Indeed, FCC administrators channel Eaman and Iaka onto VCAL paths and toss them into classes (including ours) they do not choose. Dispirited, Eaman often arrives at school tired after playing basketball until late hours. Moreover, he is harassed for uniform policy "violations" not equally applied to all students. For example, Lew witnessed a hall monitor assign him after-school detention for "wrong-color shoelaces." A White male student from the "accelerated" cohort, also witnessing it, later exclaimed (after the monitor left), "This is institutional racism!," noting that he didn't always meet all uniform criteria but had never received detention. Eaman, upset, told Lew that FCC made his father sign a contract whereby "further violations" could mean suspension, adding: "They are trying to get rid of me," thus taking in the institutional message that the school writes him off.

Geri's pointed questions imply that Eaman and Iaka should expect their dubious optimism to be cruelled in actual, unfolding futures. Dialogue then shifts to her and Tanya, who express the opposite of doxic optimism:

Tanya: I don't want to go anywhere in life.

Iaka: What?!

Tanya: I don't want to go to Uni.... My mum [is now in Uni] ... and all of the work that she is doing is crazy ... She has no life now.

Eaman: You are going to change your mind. She is going to think about it.

Tanya: It is really hard for her to pay all of the bills ... [She] goes to work, goes to Uni, comes home, works ... I haven't had a conversation with my mum since she started Uni, like a proper, actual conversation.

Geri: That's what I am so not looking forward to ... it is so pointless. You go to school to Year 12 and then study for another fifteen years of your life? What the hell, I would rather ... [get] an alright paying job, live in a shack and just get drunk on weekends.

Tanya's bleak pessimism - effectively a dead-future hypothesis - shocks Iaka and 
Eaman, who, as we read it, plead for her not to haunt their optimistic doxa to such an extreme. Tanya had, in Year 9, moved states to live with her mother, fleeing her father's alcoholism. Geri, who echoes Tanya's sense of "pointlessness," has been subject to drug and physical abuse in homes of both her separated parents, never living stably with either, and, from a young age, accumulating troubles outside of home-life. Like focusgroup students, but more acutely, their bleak sense of future life-chances reflects, and extrapolates beyond, parents' struggles. However, while the "selected" students' firstgeneration-in-university parents later hit mid-life walls, Tanya's "lower" working-class mum started out up against structural walls and now, in mid-life, gambles on university to improve her prospects. To Tanya, her sufferings expose cruel miseries of this meritocratic doxa.

\section{Identity labors around racism}

While Eaman fantasized optimism about a "businessman" future, more important - in terms of curriculum potential to convert funds of knowledge (FK) to funds of identity (FI) - was the "dark"-yet-rich FK he contributed to group dialogue about experienced racist dynamics. Early on, he and Iaka recounted an experience in a Fringe City (FC) shop:

Iaka: Yesterday, we were walking around in Target [a low-end department store] because I wanted to buy some hair gel, but we stand there for not even a minute ... Eaman: They called the managers to watch out for us.

Iaka: It was over the loud speaker.

Eaman: We got angry: like, let them come and we will see what they are going to do. But they didn't come to us; they just kept walking around us, checking us out.

When, in their research, the group talked with an Aboriginal-Australian academic (Arlene), Eaman articulated further on shop-surveillance experiences: 
Arlene: Eaman, Lew was telling me about [you] going in shops and stuff?

Eaman: I went into a shop [in FC] and was actually buying stuff, and they kept following me. But [I saw] another guy ... [who] was actually filling his shirt under his pants. And they kept searching my bag but they let the White guy go.

Arlene: Do you go back to those shops?

Eaman: If I really have an argument with them and get kicked out, I am proud of it. I have got used to it; it's normal to me.

Geri: You shouldn't think that is normal.

Eaman: What am I supposed to do about it?

Institutional-racist surveillance of Black African youth - stereotyped as likely thieves is not unknown to Geri, who has African friends at FCC. Yet Eaman expands her understanding that, for Black Africans in Australia, such experience is unavoidably "normal," but that, in turn, it becomes a counter-norm for him (and, by implication, many other young Black Africans), to expose, through proud argument, the injustices masked by dominant societal "norms" of multi-cultural equality. Soon after, the group interviewed wife-and-husband owners in their Ethiopian restaurant in FC, who treated them to a cultural coffee ceremony with cakes. In group dialogue back in the classroom, Geri recalls Eaman's stories of shop surveillance and observes the contrast:

Geri: But not if you go into a shop where someone of the same color as you?

Eaman: From an African shop, no.

Geri: Yeah, ... they [were] all like: "Hey, how are you going?" ... [and] I feel like I am intruding; like, "Oh my God, I am White."

Eaman: But they never follow you.

Geri: They give you that benefit of a doubt. They don't stereotype us, so I don't understand why we have to do it to them. They are not racist to us.

Such identity labors around "Black"-“White" power relations was taken further in a strong moment of the group interview with the Aboriginal academic. Eaman broached a different order of racist dynamics, beyond shop surveillance, in a suburb three miles from FC where his family and many other African refugees lived in high-rise buildings: 
Eaman: Something happened to my cousin, he got killed. He got murdered.

Arlene: No!

Eaman: Yeah. But a week before he died he got bashed by cops.... They took him to a corner and bashed him.

Arlene: How old?

Eaman: He was twenty, I think.... I reckon the Police have covered everything up, because when they found him in the [river], cops said to his mum that nothing [violent] happened to him. And then when she went and checked, his eyes were, like, out and everything.

Through his stories replete with dark-yet-rich FK, Eaman teaches the group, including Lew, a spatial geography of differences in "race"-relations ${ }^{3}$ across Melbourne suburbs, shops, restaurants, other businesses, schools, police stations and further social spaces. Some suffer relentless racism, others little or none, in the identity dynamics by which "selfhood" is assigned in relation to "others." Back in classroom dialogue, Geri seeks to expand the spatial-geographic frame further, asking Eaman about comparative life in Ethiopia (to where his family originally fled from Sudan):

Geri: Was it different? ... A happier community than what it is in FC? Eaman: You struggle to live there too ... [but] yeah, they are way friendlier.

Geri: So everyone helps everyone?

Eaman: Yeah.

Geri: So that's like, the real meaning of community when people help people.... There is no community in FC [like that].... I would rather struggle and be happy than not be happy.

Tanya: Everyone takes care of each other; so, if you need bread, just walk down to your neighbor's house and like, hey?

Eaman: I used to walk into my neighbor's house all of the time, like I didn't even know them.

\footnotetext{
${ }^{3}$ We put "race" in scare-marks to indicate our political caution to signify a constructed, not natural, sense of this term.
} 
Distinctive qualities of "community" in different social spaces carry over thematically, for Geri and Tanya, in later dialogue with Lew.

\section{Real community means "acceptance"}

The group conducted interviews about FC "race" relations with people in two local food places. One, which we here call SoupKitch, cooked vegetarian food in bulk, offered free to those in need while taking voluntary donations from those who could afford, drawing a range of both down-and-out and middle-to-professional class frequenters. The other, here called ArtsCaf, was an after-work and evening café frequented mainly by middleto-professional classes drawn to good coffee, medium-priced food, and performing arts events featuring diverse ethnic groups living in/around FC. Geri and Tanya seemed fascinated by SoupKitch, leading the group there many times to interview frequenters and workers.

Lew: What draws you to Soupkitch?

Geri: There's a different connection [among] the people in Soupkitch [compared to] people in the [wider] community [...]

Tanya: Because they accept each other in Soupkitch!

Geri: Yeah. They go there for acceptance and ... to be a part of something they need. They are not there for themselves, they are there for each other.

Tanya: And the people who make all of the food, they're obviously enjoying it. Because they get to make people happy with their food and you can just see that they are not bored, they are not tired, they are not annoyed by the different people. Geri: Yeah, they are not like another day at work. It's another day to help people. Tanya: To give people a chance. Working at Hungry Jacks is just, "I want to get out of here."

The two seize on a keyword, acceptance, to give ethical-aspirational value to what they experience as a rare mode of social relation: an un-self-centered being "there for each other." They sense this special relationality among people eating, milling and 
working in SoupKitch. The group had interviewed workers there - some paid, some volunteers - who told of how, arriving in the FC area as refugee-immigrant people of color, they relied on SoupKitch as a place for food and social connection to others who struggled. Said one interviewee, "SoupKitch saved us!" Their wish to give such chances to others, and palpable enjoyment in doing so, induces Geri and Tanya to identity labors of reflection on emotively "dark" FK inherent in their work experience - feeling bored, tired, annoyed by customers - as cheaply paid part-timers (after school) at a fast food outlet. Lew pursues the contrast:

Lew: Let's work with that: that's really important.... I think you're saying that most work in this society is alienated. Do you know what I mean?

Tanya: It's drowning everyone.... Yeah, I feel, when I walk into Soupkitch, extremely accepted. So I can be myself.

Geri: And acceptance is a very, very big thing! ... I feel that I connect to a lot of people in SoupKitch. I can sit down next to a random person and just feel comfortable to tell them my life story because I know that I will get that in return, and I will get respect and they won't judge me.

With ethical-emotive crescendo, Tanya and Geri re-affirm that a social setting where people feel "extremely accepted" is a "very, very big thing." Geri articulately amplifies the inter-relational dynamics in which a diverse class-and-ethnic mix - people living both well, and rough (the underclass position where Geri identifies herself) create a unique communicative climate of non-judgmental respect and egalitarian reciprocity. We suggest that Tanya and Geri are spurred to identity labors of contrast with their dark FK experiences of feeling othered, rather than accepted, in more typical mixed-class social settings. Such is articulated by Geri when Lew prompts further comparative spatial analysis, bringing in ArtsCaf:

Lew: And if you compare - which is a good way to analyze things - ArtsCaf? 
Geri: We went for coffee there and I kind of got the upper class feel; kind of yuppie - not in a bad way ... [but] at SoupKitch we can just go in and they give us a plate, and everyone's a part of [it].

Lew: ArtsCaf represents a kind of community that is probably for people who are more professional ... it tolerates diversity, but it isn't as diverse.

Geri: This is what I have written down on paper: it goes Soupkitch and underneath I have acceptance; then I have got, on the other side of the page, ArtsCaf and I have got tolerance. And there's a very big difference between acceptance and tolerance. Accepting something is seeing it for what it is and what it can be; and tolerant is putting up with it. And then there is our school, which is not accepting or tolerant.

In response to Lew's pedagogic prompt, Geri explicitly opens what had been an implicit axis of identity work, around social-structural relations of class difference. Feeling ArtsCaf as "upper-class" and "yuppie," she senses her "lower" class-relational placement in that space; whereas she feels "part of it" in the egalitarian diversity of SoupKitch ambiance. Geri then makes a remarkable linguistic-analytical comparison. We find her contrast - "putting up with it" (tolerance), as against a future-emergent seeing "what it can be" (acceptance) - to resonate with Derrida's (2001) contrast of "tolerance" and "hospitality." Compared to "tolerance," which Derrida defines in worldly terms, he stages "hospitality" as a stand-in term for an un-definably "hyperbolic ethics" - "an ethics, therefore, that carries itself beyond [institutional] laws, norms" (p. 35) - signifying an impossible yet insistent urgency for "justice" (also a hyperbolic ethical term). We suggest that Geri's and Tanya's "acceptance” carries just such ethical surcharge into their identity labors.

Coming back to institutionalized worlds, Tanya and Geri extend socio-analysis beyond food spaces, diagnosing how the school is "not accepting or tolerating":

Tanya: When I look around [school] everyone is ... depressed that you have to wear the same uniform: the same white socks, the same shoes, the same everything 
... It makes me feel really shitty because people aren't allowed to express themselves.

Geri: But at Soupkitch you could go in dressed like a million bucks or two cents.... I reckon that I have been multi-culturalized: like, the Ethiopian girls that are here; they're really, really smart, intelligent girls, but they can't express themselves. Tanya: They're always so quiet.... They don't get help.

Geri: Alright, now, I have got to say this: there is no area for them to express what they know.... This school is classed as a "multi-cultural learning" school. That is complete and utter b-s because it is not multi-cultural learning.

Lew: No, the curriculum is not.

Tanya flags the symbolic violence of dress-code uniformity in suppressing diverse expression, which Geri extends to the domain of classroom work with knowledge (what Lew means by "curriculum"), highlighting an acute contradiction between FCC's: (a) multi-cultural intake of students from diverse social groups; and (b) failure to value the worth, for learning, of diverse cultural-historical knowledge that these students embody. Among the Ethiopian girls in the class, Geri recognizes funds of knowledge ("what they know") and knowledge-abilities ("really, really smart, intelligent") that they could contribute to classroom activity, but which prevailing FCC curriculum leaves "no area for them to express." She could say the same about FK that she, Tanya, Eaman and Iaka could contribute - as they do within the confines of their small research group, encouraged by Lew's invitational pedagogy - but which the wider institutional school, in writing these students off as "non-academic," lacks ears to hear.

Geri and Tanya's FK, and analytic knowledge-abilities, are expressed furtherlinking school "ability" streams ("blocks") to a spatial geography of power inequalities - in the next movement of dialogue:

Tanya: At my Grade 8 school ... [I was] a "G blocker." We had classes from block A to block G. It was a really big school, so there was heaps of ... different race, 
religion, and all that who don't [experience] acceptance in the school grounds and in different classes.

Geri: That's like Fringe City: Block A is coming off [a somewhat better-off nearby suburb]. Block G's Soupkitch ... and the [poorer, train-station] end.

Lew: This is the kind of analysis I'm talking about, that you're both very good at!

Tanya identifies herself as a lowest-level "blocker" as she explains how, in her prior school, "ability" stratifications linked to "race," class and other social-structural power relations, which Geri extrapolates to demographic differences in areas of FCC's intake. Lew, after praising their analytic capacities, next poses a question that shifts identity labors from socio-analysis that surfaces FK about power-inequalities they experience (class) and/or engage through friendships ("race") in their lives, into a re-working of FK as FI resources for an identity-laboring leap into future-imagining.

\section{A future-imaginative leap}

Lew: In terms of your future, Geri, you said to me more than once: "I reckon I'm going to flip burgers my whole life." Do you really think that's acceptable?

Geri: I know if I don't work my arse off in the next three to five years of my life, that's probably the only thing I will be guaranteed ... But I want to do hairdressing, piercings and tattoos: something I enjoy.... [P]eople say, "You have the gift of the gab"; and I reckon I can start a conversation with anyone.

Lew: The sense that you can be part of a community - is that what you're saying?

Geri: I can make community; I can do what Soupkitch can do, open a salon for people to come and get free haircuts, or pay as they feel, 'cause it's things that people need.

Tanya: That would be cool, if you had a pay-as-you-went hairdressing salon!

Geri here re-tests her lifeless hypothesis of a burger-flipping future in the dialogic flow of her and Tanya's analytic comparisons of different social spaces, from which SoupKitch community relations inspire new potentialities. Their excitement about the imagined salon contrasts notably with the pessimistic moods they expressed early in the 
semester (and also the pessimism reached by FCC's "selected" students in focus-group dialogues). While their pessimism about futures expressed "dark" FK from life-world/ school-world experiences based in power-marginalized social-structural positions, the curricular research that brought them into SoupKitch's ambiance, and into pedagogic dialogue comparing it with more typical spaces of social relation, fuel ethico-emotive FI vitalities for imaginative leap to an alive hypothesis. Their identity labors thus reach an optimistic future-imaginary: of small ambit, without guarantees, yet more than doxic fantasy - charged with will to believe in their agentic capacities to create alternative community around social relations of "acceptance."

\section{Conclusion: Keeping futures alive in curriculum and pedagogy}

The data-and-analyses above support FI insight that young people re-labor knowledge "funds," inherited in present life-worlds, into identity "funds" for future-imagining. Our analyses add insight, via James, that young people test outdated and simplistic hypotheses about emerging futures as they struggle for imaginative hypotheses that are not just forced and momentous but alive with believably optimistic potential. From Berlant, our analyses take insight that current times present young people - especially from power-marginalized social positions - with "cruel," or "dark," material-historical conditions for optimism about futures. Indeed, our data show young people drawing on “dark" FK in emotive labors that mostly conjure pessimistic future-hypotheses.

In this conclusion we focus on what our project's efforts suggest for curriculum and pedagogy that can vitalize agentic capacity to conjure optimistic future-potentials within/against apt senses of cruel constraints (Sellar \& Zipin, 2019). The Year 9 focus groups responded to Lew's pedagogic invitation to make their FK curricular in analytic dialogue. However, identity labors in these dialogues were held within two curricular limits: (a) isolation of students' FK from connection to the main curricular "game" of 
school subject knowledge; and (b) lack of robust processes for students to labor withand-on - to re-make - FK through active engagement with problems in life-spaces beyond school that they identify as mattering for their futures with others (Zipin 2017, 2020; Zipin \& Brennan, 2019).

In the Year 10 class, students' identity labors with-and-on their FK also lacked routes of connection into the selective curricular main game from which most in the class were written off. However, the four with whom Lew worked did bring their FK not only into analytic dialogue, but dialogue rich in identity labors with-and-on their FK, through curricular research that moved across: a "not accepting or tolerant" schoolworld; a "tolerant but not accepting" ArtsCaf; and two "acceptance" spaces. The Ethiopian restaurant's welcoming coffee ceremony re-labored Eaman's tutelage on "normal" Australian and alternative Ethiopian spaces of social relation, prompting Geri and Tanya with an impulse to re-imagine "community." Soupkitch kitchen workers then modeled an ethical-emotive re-laboring of "dark" FK associated with refugee experience in "White Australia," into a manifest joy in work that serves and builds alternative community, in turn inciting Geri and Tanya to their imaginative leap.

We lack textual space for data on the identity labors of "selected" students in the Year 10 class. We here can only state our view that, in their curricular research, they did not find ethical-emotive-analytic momentum equivalent to the four with whom Lew worked, and other "written-off" groups in the class. By way of explanation, we suggest that although, like "selected" students in the Year 9 focus group, those in the Year 10 class were skeptical of FC's school-to-university-to-life-chance hypothesis, they still had too much invested in that promised pathway to "detach from what is already not working" (Berlant). Ironically, the written-off students, in correspondingly writing school off, both grappled more acutely with cruelties of unequal "race"/class power 
relations they embodied, and seized greater degrees of freedom for future-imaginative labors that convert FK to FI.

We do not mean that identity labors convert "dark" FK to "light" FI. We do mean that young people's agentic capacities to labor towards live future-hypotheses rise in FK-to-FI conversions. We suggest further that agentic potentials are maximized if meaningful curricular bridges of dialectical connection are made across life-based FK and school-subject knowledge, bringing out the richest capacitating powers of both modes of knowledge. Thus, argues Moll (2014, p. 35), school-subject knowledge "grow $[\mathrm{s}]$ into the ... domain of personal experience, thus acquiring meaning and significance," and in turn "brings conscious awareness and control, which Vygotsky believed to be essential characteristics of schooling."

However, socially-just curricular recognition of power-marginalized young people's FK was hard-won and rare even in less cruel times, let alone with schools now under "reform" pressures from governments that translate their political crises into narrow "national curricula" and "performance" measures, aggravating long-standing selection for power-elite cultural capital. It is most difficult, then, for FK/FI projects to gain leeway from schools for rich curricular inclusion of marginalized students' FK. With students, the teachers and academics involved in such projects need ethicalaffective fuel for keeping on with FK-to-FI labors. As Berlant suggests (2016, p. 414):

\footnotetext{
What remains for our pedagogy of unlearning is to build affective infrastructures that admit the work of desire as the work of an aspirational ambivalence ... [while] absorb[ing] the blows of ... [systems that resist] adaptation and ... hold[ing] out the prospect of a world worth attaching to that's something other than an old hope's bitter echo.
}

We hope that the data we analyze from our project suggests possibilities for working with young people's ambivalent-yet-meaningful aspirations, in the process contributing 
to curricular and pedagogic infrastructures that support their knowledge-and-identity labors towards future-imaginative leaps beyond "old hope's bitter echo."

\section{References}

Appadurai, A. (2004). The Capacity to Aspire: Culture and the terms of recognition. In Y. Rao \& M. Walton (Eds.), Culture and Public Action (pp. 59-84). Stanford, CA: Stanford University Press.

Berlant, L. (2011). Cruel Optimism. Durham, NC and London: Duke University Press.

Berlant, L. (2016). The Commons: Infrastructures for troubling times. Environment and Planning D: Society and Space, 34(3), 393-419.

Brown, P., Lauder, H., \& Ashton, D. (2011). The Global Auction: The Broken promises of education, jobs and incomes. New York: Oxford University Press.

Derrida, J. (2001). On Cosmopolitanism and Forgiveness. Trans. M. Dooley \& M. Hughes. London: Routledge. (Original work published 1997.)

Esteban-Guitart, M. (2016). Funds of Identity: Connecting meaningful learning experiences in and out of school. New York: Cambridge University Press.

Esteban-Guitart, M., \& Moll, L. (2014a). Funds of Identity: A new concept based on the funds of knowledge approach. Culture \& Psychology, 20(1), 31-48.

Esteban-Guitart, M., \& Moll, L. (2014b). Lived Experiences, Funds of Identity and Education. Culture \& Psychology, 20(1), 70-81.

Gramsci, A. (1971). Selections from the Prison Notebooks. Translated \& Edited by Quintin Hoare and Geoffrey Nowell Smith. New York: International Publishers.

James, W. (1897). The Will to Believe and Other Essays in Popular Philosophy. New York: Longmans, Green, and Co. https://www.gutenberg.org/files/26659/26659h/26659-h.htm. Accessed September 2019.

Moll, L. C. (2014). L.S. Vygotsky and Education. Hoboken, NJ: Taylor and Francis.

Moll, L. C., Amanti, C., Neff, D., \& González, N. (1992). Funds of Knowledge for Teaching: Using a qualitative approach to connect homes and classrooms. Theory into Practice, 31(2), 132-141.

Muller, J., \& Young, M. (2019): Knowledge, Power and Powerful Knowledge Revisited, The Curriculum Journal, 30(2), 196-214.

Pusey, M. (2003). The Experience of Middle Australia: The dark side of economic reform. Port Melbourne: Cambridge University Press. 
Sellar, S., \& Zipin, L. (2019). Conjuring Optimism in Dark Times: Education, affect and human capital. Educational Philosophy and Theory, 51(6), 572-586.

Subero, D., Vujasinović, E., \& Esteban-Guitart, M. (2017). Mobilising Funds of Identity in and out of school, Cambridge Journal of Education, 47(2), 247-263. Standing, G. (2011). The Precariat: The new dangerous class. London: Bloomsbury Academic.

Zipin, L. (2009). Dark Funds of Knowledge, Deep Funds of Pedagogy: Exploring boundaries between lifeworlds and schools. Discourse: Studies in the Cultural Politics of Education, 30(3), 317-335.

Zipin, L. (2013). Engaging Middle Years Learners by Making their Communities Curricular: A funds of knowledge approach. Curriculum Perspectives, 33(2), 112.

Zipin, L. (2017). Pursuing a Problematic-Based Curriculum Approach for the Sake of Social Justice. South African Journal of Education, 69, 67-92.

Zipin, L. (2020). Building Curriculum Knowledge Work around Community-Based "Problems that Matter": Let's dare to imagine. Curriculum Perspectives, 38(1), 111-115.

Zipin, L., Sellar, S., \& Hattam, R. (2012). Countering and Exceeding 'Capital': A 'funds of knowledge' approach to re-imagining community. Discourse: Studies in the Cultural Politics of Education, 33(2), 179-192.

Zipin, L., Sellar, S., Brennan, M., \& Gale, T. (2015). Educating for Futures in Marginalized Regions: A sociological framework for rethinking and researching aspirations. Educational Philosophy and Theory, 47(3), 227-246.

Zipin, L., \& Brennan, M. (2019). Pursuing Pragmatic-Radical Curriculum Democracy: Students as co-researchers on problems that matter. In S. Riddle \& M. W. Apple (Eds.), Re-imagining Education for Democracy (pp. 56-73). London: Routledge. 